\title{
The process approach to increasing environmental friendliness of transport and logistics services
}

\author{
Daria Varlamova ${ }^{1}$ and Alexander Gorovoy ${ }^{1, *}$ \\ ${ }^{1}$ Saint Petersburg National Research University of Information Technologies, Mechanics and Optics, \\ 49, Kronverksky Pr., 197101, St. Petersburg, Russia
}

\begin{abstract}
The article considers the use of the concept of integrated approach to manage transport and logistics services with elements of modern logistics technologies and total quality management. The author proposes the process model of quality management for the transport services. The using of this model can help the organization to define logistics processes of a high-priority and to redirect resources for the efficiency and quality improvement of selected transport and logistics processes. It can help to solve the environmental problems caused by modern transport. The author offers the directions of quality improvement based on the integrated approach and results of its application.
\end{abstract}

\section{Introduction}

Issues of transport and logistics services include both the field of logistics management and of quality management. However, it is impossible to provide integration of transport logistics in the overall logistics system of the enterprise only by building an appropriate organizational structure and implementation of quality management system in logistics processes. To ensure the quality of transport and logistics services, two components are important. Firstly, organizing the strategic management at the enterprise based on modern logistics technologies, and secondly, total quality management. This integrated approach ensures the efficiency and quality of logistics processes in the corporate management structure. Improvement of logistic process in turn will allow reducing the negative impact of the transport for the environment.

\section{Methodology}

The transport services of the enterprise have three following forms:

1. The transportation of goods within the organization.

The transportation of goods is carried out from one unit to another. This is the provision of services to inner consumers.

2. The provision of transportation services as optional ones.

\footnotetext{
*Corresponding author: angela-1309.m@yandex.ru
} 
In this case, the main contract of supply or sale contains a condition for the provision of additional transport services to the consumer. In the other words, the seller is responsible to sell the relevant goods and deliver them to the point, which is mentioned in the contract and convenient for the buyer. Terms of delivery can be adjusted by Incoterms rules, bilateral agreements or other standards and norms accepted by both participants of the agreement.

3. The rendering of transport services by the third parties. The modern level of logistics, which includes the 3PL (third party logistics) participation, and, in some cases, the 4PL (fourth party logistics), provides full customer service including:

- Optimization of logistics costs,

- Monitoring, support and control of cargo movement,

- Customs services,

- Warehousing services,

- Expert and consulting services,

- Other transportation management functions (for the fourth party logistics).

Transport services as well as services in general have certain characteristics:

- Inseparability from the source,

- Intangibility,

- Lack of ownership (possession of the service for a limited period of time),

- Fragility,

- Inability to be stored,

- The variability of quality.

The variability of quality means that the quality of service depends on both objective and subjective reasons. The objective reasons include the parameters of service provision, constraints, control actions and others. The subjective reasons include communication, mutual understanding with the client and other reasons. To avoid the variability of quality or reduce its level allows following the requirements of various standards and regulations in the quality field.

However, many authors mentioned the problem of assessing the level of service delivery $[1,2,3,4]$. It should be noted that the quality can be accessed in terms of the fact how the service provider fulfills its obligations [6] as well as how the consumer accepts the quality of the product $[5,6,7]$. The application of the standards requirements allows combining the vision of both the supplier and the customer of the transport service, and to give the process of providing services the normative value of the standards requirements. Depending on the form of transport services, it is possible to develop and use different standards: internal, industry, international, as well as different rules, agreements and regulations (Table 1).

Table 1. Standardization of transport services.

\begin{tabular}{|c|c|c|c|c|}
\hline & & \multicolumn{3}{|c|}{ Standards and norms } \\
\hline & Level of transport services & 1 & 2 & 3 \\
\hline 1 & $\begin{array}{l}\text { Transportation of goods inside } \\
\text { the organization }\end{array}$ & $\begin{array}{l}\text { Inner standards, } \\
\text { quality policy, } \\
\text { instructions }\end{array}$ & & \\
\hline 2 & $\begin{array}{l}\text { The provision of transportation } \\
\text { services as optional ones }\end{array}$ & $\begin{array}{l}\text { Inner standards, } \\
\text { quality policy, } \\
\text { instructions }\end{array}$ & $\begin{array}{c}\text { Terms of } \\
\text { contracts, industry } \\
\text { standards }\end{array}$ & \\
\hline 3 & $\begin{array}{l}\text { The rendering of transport } \\
\text { services by the third parties }\end{array}$ & $\begin{array}{l}\text { Inner standards, } \\
\text { quality policy, } \\
\text { instructions }\end{array}$ & $\begin{array}{c}\text { Terms of } \\
\text { contracts, industry } \\
\text { standards }\end{array}$ & $\begin{array}{c}\text { Service } \\
\text { standards, } \\
\text { international } \\
\text { standards }\end{array}$ \\
\hline
\end{tabular}

The description of transport services contained in the standards and documents of the organization is intended to improve their efficiency for both internal and external customers and for the organization itself in the frames of its activities. 
There are different approaches to the definition of efficiency:

- Resource-cost approach, defined as the ratio of the enterprise work results to the costs of this work, which ensure the quality;

- Goal-oriented approach, based on the determination of the compliance of the results achieved with the previously set goals;

- Analytical approach involving operational analysis, which allows diagnosing the current state of affairs, identifying unused factors, as well as providing opportunities and reserves;

- Logistics approach based on consideration of all processes of enterprise activity as logistics;

- Quality-based approach and others.

Each of these approaches is important and contributes not only to the definition of criteria for the efficiency of transport services but also to the improvement of this efficiency $[8,9]$.

Let us consider the relationship between logistics and quality of transport services. The logistics concept of quality, which is currently used, ensures the impact of the quality management system on the logistics system of the enterprise to improve the quality of services. Moreover, logistics methods and tools are also used as an object in quality management.

The main basic function of logistics in this context can be called "end-to-end" quality of transport services at all stages of the enterprise activity. Integration of logistics and quality processes in the provision of transport services can be presented in the following scheme (Figure 1).

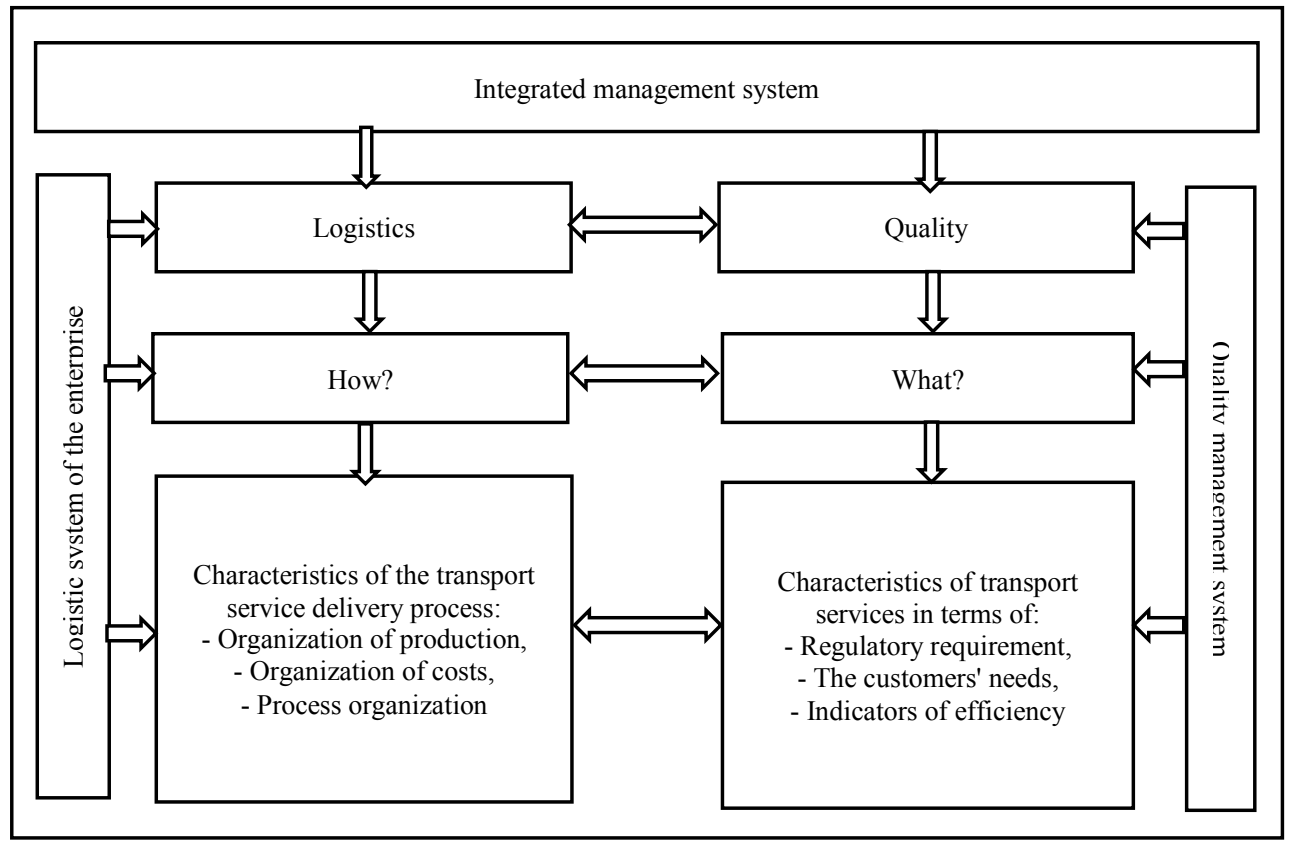

Fig. 1. Integration of logistics and quality processes in the transport service delivery.

The formation of the service delivery process consists of several stages. Therefore, the stages of service delivery form a kind of logistics chain, where the output of one process is the input to the next process. At each stage of such logistics chain, the impact of the transforming quality parameters for these services should be taken into the account (Figure 2). 


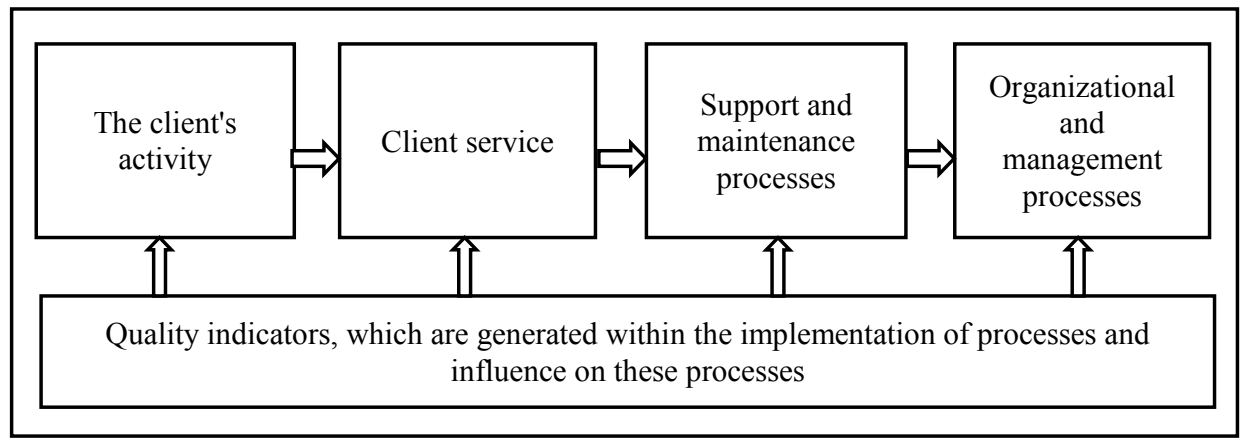

Fig. 2. Logistics chain from the viewpoint of the quality of transport services.

In that way each subsequent stage of the logistics chain of transport services transforms the quality of services, which allows managing the quality in terms of logistics parameters as well as maintaining the current quality indicators for each logistics link $[10,11]$.

\section{Result}

For the implementation of the general integrated management of the processes of transport services and the organization of the transport logistics system at the enterprise it is proposed to form the following model of quality management of transport services (Figure 3). The implementation of the process approach will track changes in indicators, rank them by importance and highlight the most important and necessary ones. In the scientific literature, there were made some attempts to apply the process approach to the management of logistics processes [12]. The following model is an integration of logistics processes, quality management and business process management of the organization.

This model involves four successive steps:

1. The stage of formation of processes, including their identification, the definition of business processes followed by the construction of links between them.

The purpose of the stage is to identify the existing processes in the field of transport and logistics services and their relationships for the subsequent effective management. The content of the stage includes the selection and classification of transport and logistics functions and operations performed by the organization; identification of those actions that are superfluous or ineffective and do not carry a significant semantic load; systematization of selected functions and operations for further work with them; selection of approaches for determining business processes; determination of the characteristics of business processes, such as boundaries, inputs and outputs, owners, content; building links between identified business processes taking into the account their functioning both in the internal and external environment. The result of the stage is to obtain a system of relevant business processes that require subsequent management.

2. Process management stage, which includes four types of management: information management, financial management, resource management and regulatory management.

The purpose of the stage is the integration of the formed system of processes in the management system of the enterprise. The content of the stage includes information support of logistics business processes, including the use of the process approach, the creating of information base and the inclusion of processes in the overall enterprise management system; financial management of processes, including the formation, analysis and management of costs and budget; management of various types of resources as well as their provision; regulatory management of processes due to the system of internal and external 
document management, including the requirements of standards and regulations, terms of contracts, legislative and other regulatory framework. The result of the stage is to build an effective management system taking into the account the processes identified at the previous stage.

3. Stage of process monitoring and control, which provides continuous and operational monitoring of business processes.

The purpose of the stage is to improve the efficiency of process management through operational monitoring and tracking, carried out in a continuous mode. The content of the stage contains the daily monitoring of functions and operations, implementation of constant control for making operational decisions as well as timely detection of emerging challenges and mistakes and their correction. The result of the stage is the transition to the next, final stage of management as well as the accumulation of material for further analysis and evaluation of the work carried out.

4. Stage of process analysis and evaluation, which includes seven types of analysis: problem diagnosis, trend analysis, profile analysis, point analysis, comparative analysis, assessment and forecasting.

The purpose of the stage is to evaluate the parameters of the process for its further optimization, and the result is to improve the efficiency and quality of processes. The content of the process includes the following actions:

- Diagnostics of challenges and mistakes identified at the previous stage as well as determination of their complexity, severity of consequences and possibility of elimination (if they were not promptly eliminated at the stage of their detection);

- Trend analysis that allows assessing the level of identified problems and the state of processes in general and determining the patterns and directions of their development in the future;

- Profile analysis, which purpose is to determine if the organization is ready to implement possible changes related to solving problems in process management;

- Point analysis providing use of a point assessment to determine the condition of the problems revealed for the purpose of their further systematization and determination of organization behavior;

- Comparative analysis, providing an assessment of the situation before and after the problem solving, the rating formation of the identified indicators and comparing them with each other;

- Assessment of the situation to determine the direction of further process development;

- Making a forecast and action plan in order to improve the efficiency and quality of processes in the field of transport and logistics services.

The input into the model is the purposes and criteria for the delivery of transport and logistics services, and the output is the level of service quality. Control actions are the quality requirements established by standards and other rules in the field of quality, disturbing influences are various restrictions in the field of quality (level of employees' qualification, communication mistakes with the customers, environmental conditions and others) $[13,14]$. The results of the proposed model of quality management of transport services are as follows:

1. Prioritization of processes that increase the efficiency of transport and logistics services in terms of their quality.

2. Reallocation of the organization resources, taking into the account the priority of processes.

3. Investment increase in long-term directions and processes, reduction or complete cessation of investment in processes that play a secondary role or are identified as unnecessary for organization.

4. Improving the efficiency of the organization as a whole. 


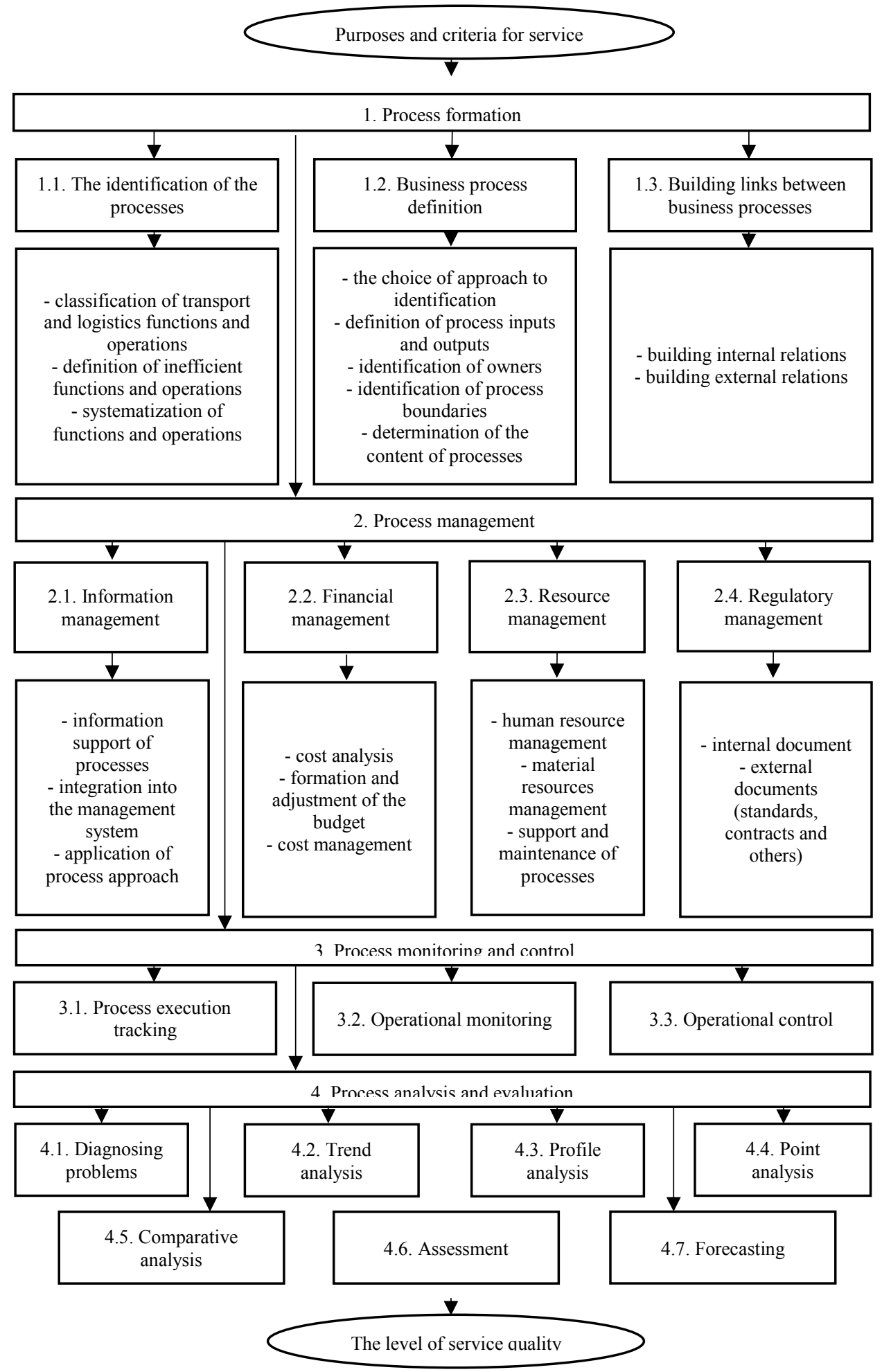

Fig. 3. Process model of quality management of transport services. 


\section{Conclusion}

The ratio of logistics and quality in the field of transport services as well as their interdependence and mutual influence require the development of an integrated approach. From the viewpoint of such approach, the use of an integrated management system combines the logistics system, quality management system and the requirements of the general management of the organization for the most effective management of transport and logistics processes. The proposed process model of quality management of transport services demonstrates the general directions and opportunities for the organization in this area, describes the main stages and conditions for improving the quality of services and contains recommendations for the use of the necessary tools and documentation. This model can be used for further work on issues of quality of transport services, the construction of the system transition of the organization to more effective management of services, the development and implementation of algorithms and schemes of the management system restructuring at the enterprise.

\section{References}

1. A.A. Antonova, Vestnik of Saratov State Socio-Economic University 1(60), 17-21 (2016)

2. P.M. Byrne, W.J. Markham, Improving Quality and Productivity in the Logistics Process (Council of Logistics Management, Oak Brook, IL, 1991)

3. A. Mottaeva, E. Vasilyeva, MATEC Web of Conferences 239, 04019 (2018)

4. A.V. Ivanova, Logistics and Supply Chain Management 3(62), 24-33 (2014)

5. J.T. Mentzer, D.J. Flint, G.T.M. Hult, Journal of Marketing 65(4), 82-104 (2001)

6. M. R. Linders, Supply and inventory management: Logistics (Council of Logistics Management, Oak Brook, IL, 2008)

7. V.S. Lukinskij, T.G. SHul'zhenko, Logistics and Supply Chain Management 1(42), 7086 (2011)

8. A. Mottaeva, MATEC Web of Conferences 193, 01022 (2018)

9. E. Vasilyeva, I. Polyakova, MATEC Web of Conferences 239, 08018 (2018)

10. A. Polyakova, E. Vasilyeva, N. Vorontsova, IOP Conference Series Earth and Environmental Science 90(1), 012136

11. A. Mottaeva, B. Melovic, MATEC Web of Conferences 193, 01002 (2018)

12. G. Dyakova, S. Izmaylova, A. Mottaeva, E. Karanina, IOP Conf. Series: Earth and Environmental Science 90, 012218 (2017) doi :10.1088/1755-1315/90/1/012218

13. As. Mottaeva, MATEC Web of Conferences 106, 08072 (2017)

14. J.T. Mentzer, D.J. Flint, J.L. Kent, Journal of Business Logistics 20(1), 9-32 (1999) 